\title{
REGIME CHANGES IN MONETARY POLICY AND THE EXPECTATION HYPOTHESIS OF THE TERM STRUCTURE IN TURKEY
}

\author{
K. Azim Özdemir ${ }^{1}$, Özgür Özel ${ }^{2}$ \\ The Central Bank of Turkey, Research and Monetary Policy Department, \\ Istiklal Cad. No. 10 Kat.16, 06100-Ulus Ankara, Turkey \\ E-mails: ${ }^{1}$ azim.ozdemir@tcmb.gov.tr; \\ 2ozgur.ozel@tcmb.gov.tr (correspondingauthor) \\ Received 31 January 2011; accepted 30 May 2011
}

\begin{abstract}
In this study we test the long-run validity of the Expectation Hypothesis of the Term Structure (EHTS) in Turkey by using monthly interest rate series from $2003 \mathrm{~m} 1$ to $2010 \mathrm{~m} 1$. The data set is obtained from the bonds and bills market for the government securities in the Istanbul Stock Exchange (ISE). Several results arise from our empirical analysis. First, we find strong evidence that there are stationary combinations of the long and short rates during the sample period. Secondly, when we restrict the cointegrating vectors to be the spread vectors between short and long rates we are not able to reject the restriction if the dynamic specifications of the systems include 2 lags of the interest rates. This result, however, is not robust to the lag length of 4 and 6 if the systems include interest rates with maturities longer than 6 months. Finally, the formal stability test results suggest that the regime change from the implicit to the full-fledged inflation targeting (IT) has no significant effect on the relationship among the interest rates on the short end of the term structure while the structural instability found in the relationship between the short rates and the long rates with maturity longer than 6 months might indicate the effect of the regime shift on this relationship. These results are in line with the conclusions of the literature that argues the EHTS to hold for the short end of the term structure when the focus of the monetary policy is to stabilize the short-term interest rates.
\end{abstract}

Keywords: term structure of interest rates, Expectations Hypothesis, cointegration, Turkey, structural stability, monetary policy, inflation targeting.

Reference to this paper should be made as follows: Özdemir, K. A.; Özel, Ö. 2012. Regime changes in monetary policy and the Expectation Hypothesis of the term structure in Turkey, Journal of Business Economics and Management 13(2): 261-274.

JEL Classification: E43, E52, C01, C13, C22.

\section{Introduction}

A leading analytical tool to understand the relationship among the yields and maturities of various bonds is the Expectation Hypothesis of the Term Structure (EHTS). The EHTS says that the long rate is a weighted average of expected future short rates over the life of the long bond, plus a stationary risk premium. This equivalently means that 
the difference between the long rate and short rate is the sum of a weighted average of expected changes in future short rates and a function of the risk premium. The main implication of the EHTS is that changes in the slope of the term structure can be used to forecast changes in the future path of the interest rates, which may be related to the future stance of monetary policy. The purpose of this study is to test the long run validity of the EHTS for Turkey as the economy underwent some important structural changes in the formulation of monetary policies in the aftermath of the 2001 crisis.

The necessary condition for the EHTS is that interest rates of different maturities are cointegrated and in a set of $n$ rates, the $(n-1)$ cointegrating vectors are the spreads between any $(n-1)$ pairs chosen from the set. While some studies report the validity of this condition for the monetary regimes in which central banks target interest rates (Hall et al. 1992; Hansen, Johansen 1999; Lardic, Mignon 2004; Beechey et al. 2008), there is overwhelming evidence that the short-run implications of the EHTS fail across different monetary regimes (Campell, Shiller 1991; Hardouvelis 1994; Sarno et al. 2007). In particular, the predictive power of the spread between long and short term interest rates do not conform to the EHTS as it fails to forecast the size and even the direction of the future short and long term interest rates.

There is a growing body of literature that attempts to explain the forecasting failure of the EHTS. The most important explanation brought forward is a time varying and persistent risk premium, which is assumed constant in the EHTS (Dai, Singleton 2002; Tzavalis, Wickens 1995; Caporale, B., Caporale, T. 2008). With this explanation, it is argued that the change in the spread might be the result of the change in the risk premium even though the expectations of the future interest rates are unchanged. Hence, the change in the spread can be even negatively correlated with the future change of the short-term interest rates. Another foremost possibility emphasized in the literature is irrational expectations of investors as long rates might overreact to movements of expected future short rates (Hardouvelis 1994).

An alternative explanation of the empirical failure of the EHTS links the failure to central bank policies. Again, there are competing views about possible reasons of the failure mainly stemming either from unpredictability or low variance of short-term interest rates (interest rate smoothing). According to Mankiw and Miron (1986), Hardouvelis (1988) and McCallum (2005) interest rate smoothing policies by central banks are responsible for the unpredictability of short-term rates and hence the broken link between the changes in the spread and the change in the short and long rates. Guidolin and Thornton (2008) also propose a similar line of explanation. They find that the forecast of long-term rates using the short-term rates do not outperform the forecasts obtained from a random walk model of the short-term interest rates ${ }^{1}$. On the other hand, some argue that the EHTS is useful to the extent that the market is able to forecast the future short-term rates, which seems to be the case during the period of controlling short-

\footnotetext{
${ }^{1}$ Carpanter and Demiralp (2009) argue that the low performance of the models in terms of the EHTS is the use of inappropriate measures for expected short rates and the omission of money market volatility.
} 
term interest rates (Carpanter, Demiralp 2009; Guidolin, Thornton 2008; Lange et al. 2003; Poole et al. 2002). Alternatively, it is also argued that when the central banks are committed to interest rate targeting, the high variance of short-term interest rates improve the performance of the simple term structure model of Expectation Hypothesis (Mankiw, Miron 1986; Rudebusch 1995; Roberds et al. 1996; Hansen, Johansen 1999), especially at the short end of the term structure.

In this study, we test the long-run validity of the EHTS in Turkey by using monthly interest rate series from $2003 \mathrm{~m} 1-2010 \mathrm{~m}^{2}$. We obtained the data from the bonds and bills market for the government securities in the Istanbul Stock Exchange (ISE). The detailed description of the data set is given in the appendix to this study. To test the long-run validity of the EHTS we used the techniques of cointegration developed by Johansen $(1988,1995,2000)$. To the best of our knowledge, there is no such study that applies this methodology to examine the EHTS using this data set. Moreover, the sample period covers the monetary regime in which various forms of the Inflation Targeting have been implemented to guide monetary policy decisions in Turkey. The Central Bank of Turkey (CBT) first adopted the Implicit Inflation Targeting framework in 2002. Following its success to anchor the inflation expectations, the transition to full-fledged Inflation Targeting regime realized in 2006. In this study, we further tested the validity of EHTS in terms of the effect of the transition from the implicit to the explicit Inflation Targeting regime. While the move from the implicit to the explicit IT regime is not a fundamental regime change in the sense that the focus of monetary policy did not shift from controlling interest rates, we still believe that it is significant enough to reinforce the role of interest rates in the monetary policy strategy. Therefore, the conclusions of this study not only provide the performance of the EHTS in Turkey, but also contribute to the literature that find significant structural breaks in the relationships among interest rates as a result of monetary regime changes (Hall et al. 1992; Hansen 1992; Roberds et al. 1996; Hansen, Johansen 1999).

Several results arise from our empirical analysis. First, we find strong evidence that there are stationary combinations of the long and short rates during the sample period. However, the cointegration spaces defined by these combinations seem to be only stable for the short end of the term structure up to six months maturity. Secondly, if we restrict the cointegrating vectors to be the spread vectors between short and long rates we were not be able to reject the restriction if we use 2 lags for the dynamic specification of the systems. This result, however, is not robust to the lag length of 4 and 6 if the systems include interest rates with maturities 6,9 and 12 months. As a result, we concluded that in our sample period the long run validity of the EHTS hypothesis cannot be rejected for the relationships among interest rates up to six months maturity for Turkey. Finally, the formal stability test results suggest that the regime change from the implicit to the full-fledged inflation targeting has no significant effect on the relationships among the interest rates on the short end of the term structure. On the other hand, the structural

\footnotetext{
${ }^{2}$ We retain 7 observations at the beginning of the sample period to ensure consistency of the estimation period as we use the alternative fixed lag lenghts of 2, 4 and 6 in the estimation.
} 
break in the relationships between the short rate and the long rates with maturity longer than 6 months might indicate the effect of this regime change. These results are in line with the conclusions of the aforementioned literature that argue the EHTS to hold when the focus of the monetary policy is to stabilize the short-term interest rates.

The rest of the paper is organized as follows. Next section discusses some theoretical considerations of the EHTS and reviews the necessary condition. The empirical strategy of the paper is presented in section III. The data is also described in this section. Section IV shows the findings of the cointegration analysis. Section VI concludes the paper.

\section{Theoretical framework}

Many researchers have concluded that interest rates are integrated of order one, i.e. $\mathrm{I}(1)^{3}$. Therefore, this led to extensive application of cointegration techniques to analyze the term structure of interest rates. The starting point of the analysis relies on a common sense approach that the behavior of long term interest rates are shaped by the current and future short term interest rates, as postulated by the EHTS. The EHTS says that the long-term interest rates are a function of current and expected future short-term interest rates with a stationary risk premium. Mathematically this idea can be expressed as follows,

$$
R_{t}^{n}=\frac{1}{n} \sum_{i=0}^{n-1} E_{t}\left(R_{t+i}^{1}\right)+v_{t}^{n} .
$$

In this equation $R_{t}^{n}$ denotes the long-term interest rates and $R_{t}^{1}$ is the one period interest rate. $E_{t}$ is the expectation operator. The expectations are assumed to be rational. Therefore, there is no systematic error when forecasting the future one period interest rates. $v_{t}^{n}$ is a stationary risk premium which might include a constant and a stable autoregressive structure, as well as iid. shocks. If we assume that interest rates are I(1), we can show the possibility of cointegration between long-term and short-term interest rates by subtracting $R_{t}^{1}$ from both sides of equation (1).

$$
R_{t}^{n}-R_{t}^{1}=\frac{1}{n} \sum_{j=1}^{n-1} \sum_{i=1}^{i=j} E_{t} \Delta R_{t+i}^{1}+\Lambda_{t}^{n} .
$$

In addition to the previous notations $\Delta$ is the one period difference operator and $\Lambda_{t}^{n}$ is a term for the risk premium after rearranging the equation. Since interest rates are I(1) and the risk premium is a stable autoregressive process, the right hand side of equation (2) is stationary. Therefore the left hand side of equation (2) also has to be a stationary process with the cointegrating vector $(1,-1)$. As shown in Hall, Anderson and Granger (1992) it follows that any interest rate of maturity $n>1$ is cointegrated with one period interest rate. As a result, given the vector of interest rates $R_{t}=\left[R_{t}^{1}, R_{t}^{2}, \ldots, R_{t}^{n}\right]$, a possible set of linearly independent spread vectors can be written as follows,

\footnotetext{
${ }^{3}$ While this is the general convention, some researchers question the unit root assumption for nominal interest rates on theoretical and emprical grounds (see Wu, Chen 2001; Beechey et al. 2008)
} 


$$
A=\left[\beta_{i}\right]=\left[\begin{array}{ccccc}
-1 & -1 & . & \cdot & -1 \\
1 & 0 & . & . & 0 \\
0 & 1 & . & . & . \\
\cdot & . & . & . & . \\
0 & 0 & . & . & 1
\end{array}\right] .
$$

Where $\beta_{i}^{\prime}$ is the cointegrating vector and $i=1,2, \ldots, n-1$. However, this is not the only possible set of $n-1$ cointegrating vectors that span the $n$ dimensional space of interest rates. Since any combination of the spread is also stationary, it is possible to derive stationary spread series, which imply cointegration between any pair of interest rates. Therefore, the cointegration space is not restricted to the spreads between the longer term rates and the one period interest rate. Any subset of $n$ interest rates whether it includes one period interest rate or not will span the cointegration space as long as it has rank $(n-1)$.

\section{Empirical findings}

The interest rate data used in this study are obtained from the bonds and bills market in the ISE. The sample period covers 2003m1-2010m1 nominal rates with 1, 2, 3, 6, 9 and 12 months to maturity. The detailed information about the data is given in the appendix to this study. As seen in figure 1 of the appendix, the interest rates display a volatile movement along with a strong decreasing trend at the beginning of the sample period. After this strong decreasing trend, however, they attain a relatively stable movement just before the full-fledged inflation targeting regime in 2005. Moreover, the standard unit root tests support the visual inspection that the series do not have a constant mean and variance. As a result the I(1) properties of the series cannot be rejected for Turkey in the sample period ${ }^{4}$.

Multivariate Cointegration analysis proposed by Johansen $(1988,1995,2000)$ is applied to analyze the relationship among the interest rate series. We prefer to use trivariate systems for the analysis, as the available number of observations might not be enough to produce reliable results for a larger system that includes all interest rate series. The trivariate systems used in the study are:

$$
\begin{aligned}
& \text { System A : } R^{A}=\left[R_{t}^{1}, R_{t}^{2}, R_{t}^{3}\right], \\
& \text { System B : } R^{B}=\left[R_{t}^{1}, R_{t}^{3}, R_{t}^{6}\right], \\
& \text { System C : } R^{C}=\left[R_{t}^{1}, R_{t}^{3}, R_{t}^{9}\right], \\
& \text { System D : } R^{D}=\left[R_{t}^{1}, R_{t}^{3}, R_{t}^{12}\right] .
\end{aligned}
$$

System A, B, C and D include interest rates with 1, 2 and 3 months to maturity, 1, 3 and 6 months to maturity, 1, 3, and 9 months to maturity and finally 1,3 , and 12 months to maturity, respectively.

\footnotetext{
${ }^{4}$ The result for the standard unit root tests can be provided upon request from the authors.
} 
One of the important problems that face the researchers in a multivariate cointegration analysis is to find out a correct dynamic specification before performing the cointegration tests. It is argued that if the lag length of the unrestricted VAR system is too small it may cause size distortion, which results in spurious cointegration. On the other hand, it is known that using too many lags reduce the power of the cointegration tests. In the literature, there is no consensus on the criteria to select the number of the lag length. For example, some authors prefer to use fixed lag lengths (Hansen, Johansen 1999; Tzavalis, Wickens 1997), while others use some information criteria such as the Akaike and Schwarz Information Criterions (Shea 1992; Silva Lopes, Monteiro 2007; Celik, Ozerkek 2009). On the other hand, Bauwens, Deprins and Vandeuren (1997) propose a methodology to start with a maximum lag length of 5 or 6 for monthly data and reduce the lag length by checking the residual autocorrelation. In this study, when we consider the size of the full sample, which is 85 observations, and the number of parameters that is needed to be estimated we take parsimony as the most important criterion in the modeling strategy. As a result, we use fixed lag lengths of 2, 4 and 6 and run a series of diagnostic tests that help to determine the correct specification of the unrestricted VAR $^{5}$. Therefore, the performance of each model can be assessed on these diagnostic test results. This strategy also enables us to check the sensitivity of the results. If the conclusions remain broadly the same across the models, we can argue that they are robust. Finally, we need to mention that the model includes restricted constant terms as a deterministic variable in order to exclude drifts in the interest rate series.

The results reported in Table 1 are for the trivariate systems of $R^{A}, R^{B}, R^{C}$ and $R^{D}$ that use fixed lag length of 2, 4 and 6 respectively. The first row of each panel of Table 1 summarizes the cointegration test results ${ }^{6}$. We computed the Barlett-corrected trace statistics $\left(\lambda_{\text {trace }}^{\text {cr }}\right)$ for cointegration test proposed by Johansen (2000). It is preferable to use this statistics, because it is robust to non-normality in the residuals and corrects the conventional trace test for small sample bias. Together with these statistics, the table also presents summary decisions based on some specification tests in order to assess the adequacy of the alternative dynamic specifications mentioned in the previous paragraph. In particular, the possibility of serially correlated residuals at lag 1 and 12 are examined in a multivariate context. Similarly, multivariate ARCH effects in the residuals are tested for the full rank. Finally, the null hypothesis of the multivariate normal distribution of the residuals of the VAR system is tested by applying the Omnibus statistic suggested by Doornik and Hansen (1994).

For each dynamic specification of the system, the table also includes the summary decisions regarding structural stability based on some formal parameter constancy tests for rank two. For this purpose, we consider the Eigenvalue Fluctuation test suggested by Hansen and Johansen (1999) and the Nyblom type tests suggested by Bruggeman, Donati and Warne (2003) (BDW). The Hansen-Johansen Fluctuation test is based on the

\footnotetext{
${ }^{5}$ We also checked the lag length selected by the Akaike Information Criterion. However, in all cases it selects 11 or 12 lags which result in overparametrization of the VAR system.

${ }^{6}$ The details of the test results can be provided upon request from the authors.
} 
examination of the sum of the non-zero eigenvalues of the cointegrated system. It is a test for the constancy of a set of parameters including both the adjustment term and the cointegrating vectors. On the other hand, the Nyblom test checks only for the constancy of the cointegration space including a constant term. The BDW version of the Nyblom test, which is used in this study, employs the score function directly instead of using the first order Taylor expansion in calculating LM statistics and thereby achieves a better numerical reliability compared to the version proposed by Hansen and Johansen (1999). Moreover, the decisions presented in the table utilize two types of the BDW version of the Nyblom test. The first is the supremum test $\left(\operatorname{Sup}_{t \in \mathrm{T}} Q_{T}^{(t)}(S)\right)$ that is derived from the maximum value of a weighted LM- statistics. The second version $\left(\operatorname{Mean}_{t \in \mathrm{T}} Q_{T}^{(t)}(S)\right)$ is the mean of this statistics over the examination period.

To check the robustness of the decisions we also computed the bootstrapped p-values for all the tests. The bootstrapped p-values are obtained from non-parametric simulations that treat the bootstrapping residuals iid. The length of each sample in the simulation is equal to the sample size of the original data and the numbers of such samples are 1000 .

As seen in the table when the lag length 2 is used, we conclude that there are 2 cointegration relations for each system at the 5 percent level. While systems B, C and D continue to support 2 cointegration relations at the 10 percent level, the significant cointegration relations increase to 3 for system A at this level of confidence. This might suggest some spurious cointegration due to using insufficient number of lags in the estimation. However, residuals from system A and C seem to be serially correlated as the null hypothesis of the no autocorrelation is rejected at the 10 percent level. In addition, there remain some multivariate $\mathrm{ARCH}$ effects in systems $\mathrm{C}$ and D. Finally, the normality of the residuals for all of the systems were accepted at the 5 percent level.

Turning to the lag length 4 the results reported in the table for the cointegration test are consistent with the results obtained for 2 lags. The cointegration test supports 2 cointegration relations for each system at the 10 percent level. On the other hand, the inclusion of two additional lags produce some improvement for the diagnostic statistics of the specifications. The LM tests for serial correlation do not reject the null hypothesis of no autocorrelation at the 10 percent level for all of the systems. While the asymptotic pvalues suggest some ARCH effect for the systems, p-values obtained from the bootstrap simulations do not support the ARCH effects at the 10 percent level. A similar result arises for the normality test. In this case, there seems to be no non-normality problem at the 5 percent level according to the bootstrapped p-values. However, at the 10 percent level the normality assumption fails for the systems B, C and D.

However, the increase of the lag length from 4 to 6 does not improve the diagnostic statistics of the estimated systems. On the contrary, the table presents that the hypothesis of no autocorrelation for the residuals of the system A cannot be accepted if we include 6 lags in the system. Moreover, the cointegration test now suggests only 1 cointegrating vector at the 10 percent level for systems A, B and C. Overall examination of the specification tests reported in the table reveals that there is no difference between choosing 2 or 4 lags, but both are preferable over 6 lags for describing the dynamics of the term structure of interest rates. 
Table 1. Decisions based on cointegration and diagnostic tests statistics

\begin{tabular}{|c|c|c|c|c|c|c|}
\hline & \multicolumn{2}{|c|}{ Lag Length 2} & \multicolumn{2}{|c|}{ Lag Length 4} & \multicolumn{2}{|c|}{ Lag Length 6} \\
\hline & $\begin{array}{c}5 \\
\text { Percent }\end{array}$ & $\begin{array}{c}10 \\
\text { Percent }\end{array}$ & $\begin{array}{c}5 \\
\text { Percent }\end{array}$ & $\begin{array}{c}10 \\
\text { Percent }\end{array}$ & $\begin{array}{c}5 \\
\text { Percent }\end{array}$ & $\begin{array}{c}10 \\
\text { Percent }\end{array}$ \\
\hline \multicolumn{7}{|c|}{ System $\mathbf{A}-R_{t}^{1}, R_{t}^{2}, R_{t}^{3}$} \\
\hline $\begin{array}{l}\text { How many cointegrating } \\
\text { vectors exist? }\end{array}$ & 2 & 3 & 2 & 2 & 1 & 1 \\
\hline Does serial correlation exist? & No & Yes & No & No & Yes & Yes \\
\hline Does ARCH Effect Exist? & No & No & No & No & No & No \\
\hline $\begin{array}{l}\text { Are the Residuals Normally } \\
\text { Distributed? }\end{array}$ & Yes & Yes & Yes & Yes & Yes & Yes \\
\hline $\begin{array}{l}\text { Is the Cointegration Space } \\
\text { Structurally Stable? }\end{array}$ & Yes & Yes & Yes & Yes & Yes & No \\
\hline $\begin{array}{l}\text { Does the restriction for } \\
\text { the REHTS hold? }\end{array}$ & Yes & Yes & Yes & Yes & Yes & Yes \\
\hline \multicolumn{7}{|c|}{ System B - $R_{t}^{1}, R_{t}^{3}, R_{t}^{6}$} \\
\hline $\begin{array}{l}\text { How many cointegrating } \\
\text { vectors exist? }\end{array}$ & 2 & 2 & 2 & 2 & 1 & 1 \\
\hline Does serial correlation exist? & No & No & No & No & No & No \\
\hline Does ARCH Effect Exist? & No & No & No & No & No & No \\
\hline $\begin{array}{l}\text { Are the Residuals Normally } \\
\text { Distributed? }\end{array}$ & Yes & No & Yes & No & No & No \\
\hline $\begin{array}{l}\text { Is the Cointegration Space } \\
\text { Structurally Stable? }\end{array}$ & Yes & Yes & Yes & Yes & Yes & Yes \\
\hline $\begin{array}{l}\text { Does the restriction for } \\
\text { the REHTS hold? }\end{array}$ & Yes & Yes & Yes & No & No & No \\
\hline \multicolumn{7}{|c|}{ System C $-R_{t}^{1}, R_{t}^{3}, R_{t}^{9}$} \\
\hline $\begin{array}{l}\text { How many cointegrating } \\
\text { vectors exist? }\end{array}$ & 2 & 2 & 2 & 2 & 1 & 1 \\
\hline Does serial correlation exist? & No & Yes & No & No & No & No \\
\hline Does ARCH Effect Exist? & Yes & Yes & No & Yes & Yes & Yes \\
\hline $\begin{array}{l}\text { Are the Residuals Normally } \\
\text { Distributed? }\end{array}$ & Yes & Yes & Yes & No & No & No \\
\hline $\begin{array}{l}\text { Is the Cointegration Space } \\
\text { Structurally Stable? }\end{array}$ & No & No & No & No & No & No \\
\hline $\begin{array}{l}\text { Does the restriction for } \\
\text { the REHTS hold? }\end{array}$ & Yes & Yes & No & No & No & No \\
\hline
\end{tabular}


End of Table 1

\begin{tabular}{|c|c|c|c|c|c|c|}
\hline & \multicolumn{2}{|c|}{ Lag Length 2} & \multicolumn{2}{|c|}{ Lag Length 4} & \multicolumn{2}{|c|}{ Lag Length 6} \\
\hline & $\begin{array}{c}5 \\
\text { Percent }\end{array}$ & $\begin{array}{c}10 \\
\text { Percent }\end{array}$ & $\begin{array}{c}5 \\
\text { Percent }\end{array}$ & $\begin{array}{c}10 \\
\text { Percent }\end{array}$ & $\begin{array}{c}5 \\
\text { Percent }\end{array}$ & $\begin{array}{c}10 \\
\text { Percent }\end{array}$ \\
\hline \multicolumn{7}{|c|}{ System D - $R_{t}^{1}, R_{t}^{3}, R_{t}^{12}$} \\
\hline $\begin{array}{l}\text { How many cointegrating } \\
\text { vectors exist? }\end{array}$ & 2 & 2 & 2 & 2 & 1 & 2 \\
\hline Does serial correlation exist? & No & No & No & No & No & No \\
\hline Does ARCH Effect Exist? & No & Yes & No & No & Yes & Yes \\
\hline $\begin{array}{l}\text { Are the Residuals Normally } \\
\text { Distributed? }\end{array}$ & Yes & No & Yes & No & Yes & No \\
\hline $\begin{array}{l}\text { Is the Cointegration Space } \\
\text { Structurally Stable? }\end{array}$ & Yes & Yes & No & No & No & No \\
\hline $\begin{array}{l}\text { Does the restriction for } \\
\text { the REHTS hold? }\end{array}$ & Yes & Yes & No & No & No & No \\
\hline
\end{tabular}

Following these results it can be argued that the rank of the cointegration for each system is consistent with the prediction of the EHTS. Since we have 3 interest rates in systems A, B, C and D, 2 cointegration relations, as presented in the table, are in line with this hypothesis. Further analysis of the cointegration spaces shows that the parameters of the cointegrating vectors remained stable for the systems A and B. However, the same cannot be argued for the systems $\mathrm{C}$ and $\mathrm{D}$, which include 9 and 12 months interest rates in addition to 1 and 3 month interest rates.

However, this is not a sufficient condition to establish the long run validity of the EHTS. It must also be the case that the cointegrating vectors that span the space of the trivariate systems are the vectors $(-1,1,0)$ and $(-1,0,1)$ which are the spread vectors. This proposition is tested for each system for lags 2,4 and 6 and its results are reported in the last rows of the table. In this respect, we used both the F test, which corrects the small sample bias, and the Log-likelihood Ratio test. As seen from these table, the null hypothesis that the restriction is valid, cannot be rejected for all of the systems, A, B, C and $\mathrm{D}$, if we use the lag length 2 . However, if we increase the lag length to 4 , there are strong evidences produced by both the F and LR tests against the null hypothesis for the systems $\mathrm{C}$ and $\mathrm{D}$ that include 9 and 12 months interest rates. The results from the $\mathrm{F}$ test, however, support the null hypothesis for the system A and B at the 5 percent significance level even if we use a lag length of 4 . While the conclusions obtained from the 4 lags specification do not change for the systems $A, C$, and D, if we use a lag length of 6 , the null hypothesis is rejected for the system B. As a result, we can argue that the EHTS cannot be rejected for the relationship between the interest rates with maturity up to 6 months as the spread vector are the cointegrating vectors, which also remained stable during our examination period. However, the spread vectors are not the cointegrating vectors for the interest rates with maturities longer than 6 months. 


\section{Conclusions}

In this study, we test the long-run validity of the EHTS in Turkey by using monthly interest rate series from $2003 \mathrm{~m} 1-2010 \mathrm{~m} 1$. To the best of our knowledge, there is no such study that examines the EHTS using the Turkish interest rates data. Moreover, the sample period covers monetary regimes in which two similar but somewhat different forms of the inflation targeting regimes have been implemented. While the move from the implicit to the explicit IT regime is not a fundamental regime change in the sense that the focus of monetary policy did not shift from controlling interest rates, we still believe that it is significant enough to reinforce the role of interest rates in the monetary policy strategy.

The empirical evidence is partly in line with the conclusions of the aforementioned literatures that argue the EHTS to hold when the focus of the monetary policy is to stabilize the short-term interest rates. First, we find strong evidence that there are stationary combinations of the long and short rates during the sample period. However, the cointegration spaces defined by these combinations seem to be only stable for the short end of the term structure up to six months maturity. Secondly, if we restrict the cointegrating vectors to be the spread vectors between short and long rates we were not able to reject the restriction if we use 2 lags for the dynamic specification of the systems. This result, however, is not robust to the lag length of 4 and 6 if the systems include interest rates with maturities 6,9 and 12 months. As a result, we concluded that in our sample period the validity of the EHTS hypothesis cannot be rejected for the relationships among interest rates up to six months maturity for Turkey. Finally, the formal stability test results suggest that the regime change from the implicit to the full-fledged inflation targeting has no significant effect on the relationships among the interest rates on the short end of the term structure while the structural instability of the relationships between the short rate and the long rates with maturity greater than 6 months may indicate the effect of the regime shift.

The main monetary policy implication of the study is that the stationarity of the risk premium enables the policy makers to infer the expectations of the future short term interest rates from the slope of the current yield curve up to six months maturity. Moreover, these results support the argument that the regime change from the implicit to the explicit inflation targeting in Turkey increased the credibility of the monetary policy as expectations about the future stance of the monetary policy became an important input shaping longer-term interest rates. However, we should not exclude the possibility that the financial turmoil in 2006 may be an alternative explanation for the instability of the cointegration relationship for longer maturities, in that the structure of the term premium for the longer end of the yield curve might have altered due to the instability in the financial markets. 


\section{References}

Akıncı, Ö.; Gürcihan, B.; Gürkaynak, R.; Özel, Ö. 2007. Devlet İç Borçlanma Senetleri İçin Getiri Eğrisi Tahmini, İktisat, İsletme ve Finans 22(252): 5-25.

Bauwens, L.; Deprins, D.; Vandeuren, J. 1997. Modelling Interest Rates With A Cointegrated VAR-GARCH Model, Core Discussion Paper 9780.

Beechey, M.; Hjalmarsson, E.; Österholm, P. 2008. Testing the Expectation Hypothesis When Interest Rates Are Near Integrated, Board of Governors of the Federal Reserve System, International Financial Discussion Papers 953.

Bruggeman, A.; Donati, P.; Warne, A. 2003. Is the Demand for Euro Area M3 Stable?, European Central Bank, Working Paper Series 255.

Campbell, J. Y.; Shiller, R. J. 1991. Yield spreads and interest rate movements: a bird's eye view, Review of Economic Studies 58: 495-514. http://dx.doi.org/10.2307/2298008

Caporale, B.; Caporale, T. 2008. Political risk and the Expectations Hypothesis, Economic Letters 100: 178-180. http://dx.doi.org/10.1016/j.econlet.2008.01.007

Carpenter, S. B.; Demiralp, S. 2009. Volatility, money market rates, and the transmission of monetary policy, ECB Workshop on Challenges to monetary policy implementation beyond the financial market turbulence, $30^{\text {th }}$ November $-1^{\text {st }}$ December 2009. Frankfurt.

Celik, S.; Ozerkek, Y. 2009. Panel cointegration analysis of consumer confidence and personal consumption in the European Union, Journal of Business Economics and Management 10(2): 161-168. http://dx.doi.org/10.3846/1611-1699.2009.10.161-168

Dai, Q.; Singleton, K. 2002. Expectations puzzles, time-varying risk premia, and affine models of the term structure, Journal of Financial Economics 63: 413-441.

http://dx.doi.org/10.1016/S0304-405X(02)00067-3

Doornik, J. A.; Hansen, H. 1994. A Practical Test for Univariate and Multivariate Normality, Discussion Paper. Nuffield College, Oxford, UK.

Guidolin, M.; Thornton, D. L. 2008. Predictions of Short-term Rates and the Expectations Hypothesis of the Term Structure of Interest Rates, European Central Bank, Working Paper Series 977(December).

Hall, A. D.; Anderson, H. M.; Granger, C. W. J. 1992. A cointegration analysis of treasury bill yields, The Review of Economics and Statistics 74(1): 116-126. http://dx.doi.org/10.2307/2109549 Hansen, B. E. 1992. Tests of parameter instability in regressions with I(1) processes, Journal of Business and Economics Statistics 10(3): 45-59. http://dx.doi.org/10.2307/1391545

Hansen, H.; Johansen, S. 1999. Some tests for parameter constancy in cointegrated VAR-models, Econometrics Journal 2: 306-333. http://dx.doi.org/10.1111/1368-423X.00035

Hardouvelis, G. A. 1988. The predictive power of the term structure during recent monetary regimes, Journal of Finance 43: 339-356. http://dx.doi.org/10.2307/2328464

Hardouvelis, G. A. 1994. The term structure spread and future changes in long and short rates in the G7 countries, Journal of Monetary Economics 33: 255-283. http://dx.doi.org/10.1016/03043932(94)90003-5

Johansen, S. 1988. Statistical analysis of cointegration vectors, Journal of Economic Dynamics and Control 12: 231-254. http://dx.doi.org/10.1016/0165-1889(88)90041-3

Johansen, S. 1995. Identifying restrictions of linear equations with applications to simultaneous equations and cointegration, Journal of Econometrics 69: 111-132.

http://dx.doi.org/10.1016/0304-4076(94)01664-L

Johansen, S. 2000. A Bartlett correction factor for tests on the cointegration relations, Econometric Theory 16: 740-778. http://dx.doi.org/10.1017/S0266466600165065 
Lange, J.; Sack, B.; Whitesell, W. 2003. Anticipations of monetary policy in financial markets, Journal of Money, Credit and Banking 35(6): 889-910. http://dx.doi.org/10.1353/mcb.2003.0044

Lardic, S.; Mignon, V. 2004. Fractional cointegration and the term structure, Empirical Economics 29: 723-736. http://dx.doi.org/10.1007/s00181-004-0206-8

Mankiw, G. N.; Miron, J. A. 1986. The changing behavior of the term structure of interest rates, Quarterly Journal of Economics 101: 211-218. http://dx.doi.org/10.2307/1891113

McCallum, B. T. 2005. Monetary policy and the term structure of interest rates, federal reserve bank of Richmond, Economic Quarterly 91(4): 1-21.

Poole, W.; Rasche, R. H.; Thornton, D. L. 2002. Market anticipations of monetary policy actions, Federal Reserve Bank of St. Louis Review 84(4): 65-93.

Roberds, W.; Runkle, D.; Whiteman, C. H. 1996. A daily view of yield spreads and short-term interest rate movements, Journal of Money, Credit and Banking 28: 34-53.

http://dx.doi.org/10.2307/2077965

Rudebusch, G. D. 1995. Federal reserve interest rate targeting, rational expectations, and the term structure, Journal of Monetary Economics 35: 245-274.

http://dx.doi.org/10.1016/0304-3932(95)01190-Y

Silva Lopes, A. C.; Monteiro, O. S. M. 2007. The Expectations Hypothesis of the term structure: some empirical evidence for Portugal, MPRA Paper 3437.

Sarno, L.; Thornton, D. L.; Valente, G. 2007. The empirical failure of the Expectations Hypothesis of the term structure of bond yields, Journal of Financial and Quantative Analysis 42(1): 81-100. http://dx.doi.org/10.1017/S0022109000002192

Shea, G. S. 1992. Benchmarking the Expectations Hypothesis of the interest-rate structure: an analysis of cointegration vectors, Journal of Business and Economic Statistics 10(3): 347-366. http://dx.doi.org/10.2307/1391547

Tzavalis, E.; Wickens, M. R. 1995. The persistence in volatility of the US term premium 19701986, Economic Letters 49: 381-389. http://dx.doi.org/10.1016/0165-1765(95)00700-P

Tzavalis, E.; Wickens, M. R. 1997. Explaining the failures of the term spread models of the rational Expectations Hypothesis of the term structure, Journal of Money, Credit, and Banking 29(3): 364-380. http://dx.doi.org/10.2307/2953700

Wu, J.; Chen, S. L. 2001. Mean reversion of interest rates in the eurocurrency market, Oxford Bulletin of Economics and Statistics 63: 459-474. http://dx.doi.org/10.1111/1468-0084.00229

\section{APPENDIX}

The interest rate data are obtained from the bonds and bills market in the ISE. By using this data set, the yield curve was estimated from 1 to 12 months maturity with three different techniques, namely Nelson Siegl (NS), Extended Nelson Siegl, and Interpolation. NS and ENS calculations are based on the MATLAB codes used in Akinci et al. (2007) paper, which proposes yield curve estimation for Turkish Treasury bonds and bills.

The NS and ENS methods conjecture a non-linear functional form for the yield curve. The application of these methods using the Turkish Treasury bills and bond data cannot provide reliable yield estimates up to 3 months maturity due to technical reasons, as explained in Akınc1 et al. (2007). Furthermore, the NS method applied to our data set provided some inconsistent results in terms of abrupt yield changes due to the small number of securities traded and the short maturity horizon we are dealing with (i.e. up to 12 months). Since the main purpose of our paper is to inquire the cointegration 
structure on the short end of the yield curve, where the 1 month yield is regarded as a proxy for the policy rate of the Central Bank of Turkey $(\mathrm{CBT})^{7}$, the inconsistency of the yield estimates and the inability of computing reliable yields up to 3 months led us to prefer linear interpolation over parametric approaches such as NS and ENS. In the linear interpolation method, however, we need a bond with a maturity of less than M months and another one with a maturity exceeding $M$ months for a return of $M$ months to exist in our data set, unless there exists a bond that has a maturity of exactly M. Using the two bonds we assign weights to their respective returns inversely proportional to their distance to $\mathrm{M}$, so the less the distance, the higher the weight is in the calculation of the return to $\mathrm{M}$ months' maturity.

We computed the yields on a monthly basis. All yields are averages of the last 5 trading days of a particular month to circumvent possible spikes. For example, the 1 month yield for November 2003 is the average of 1 month yields computed for 19, 20, 21, 24 and $28^{\text {th }}$ of November 2003. As of the starting date of the yield curve calculation, we use the launch of the implicit IT regime in 2002. However, after implementing the interpolation method, we realized that more than half of 9 and 12 months yields are missing in 2002 due to inadequate number of Treasury securities traded in that period. Therefore, we preferred to start the analysis from 2003 onwards. Consequently, at the penultimate step we are left with just a few missing observations. Fig. 1 illustrates the final data set when the missing observations are deemed zero. As seen from this graph, in the whole data period we are missing just three observations that we interpolated using their immediately past and future values, which we think does not affect the validity of the analysis.

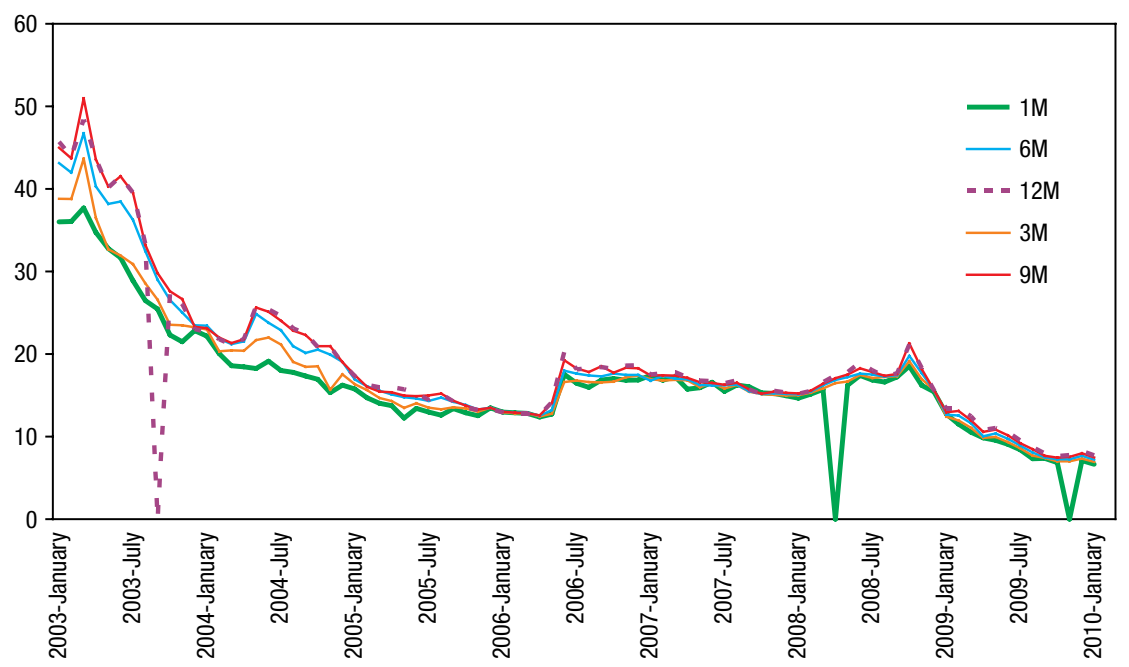

Fig. 1. 1, 3, 6, 9 and 12 Month Yields for January 2003-January 2010 period

\footnotetext{
${ }^{7}$ For the data period, the policy rate for the CBT was the $\mathrm{O} / \mathrm{N}$ reverse repo rate, however none of the methods provided can estimate the market yield for such a short maturity, hence the need for a proxy.
} 
K. Azim ÖZDEMİR graduated from Istanbul University by obtaining a B.S. degree in Economics in 1992. After several years of work experience as a bank auditor, he obtained an M.A. degree from Sheffield University in the UK. At the same university he also completed his Ph.D. degree in 2004. His $\mathrm{Ph}$.D. dissertation analyzes various issues such as the sustainability of public debt, seigniorage, Ricardian Equivalence and the interaction of monetary and fiscal policies during the high inflation period in Turkey. Currently, he is working at the Central Bank of Turkey as an economist. His main research interests are monetary economics and applied econometrics. He published several papers in refereed journals. Some of his studies are also published in the Turkish Central Bank's Working Papers Series.

Özgür ÖZEL is a Koç University alumnus. He obtained B.S. degrees both in business administration and economics in 2002. Following a one-year career as a corporate finance analyst he obtained an M.A. degree in economics from the Sabanc1 University. He has been working as a researcher at the Central Bank of Turkey since 2005. In the interim, he obtained an M.S. degree in financial mathematics from the University of Chicago. His main research areas are monetary transmission, yield curve estimation and term premium analysis. Some of his studies were published as a working paper at the Turkish Central Bank's web site. Özgür Özel is a current Ph.D. student in the financial mathematics department at the Middle East Technical University. 